\title{
SYNTHESIS OF Ti-Zr ALLOY BY POWDER METALLURGY
}

\author{
Ljerka Slokar $^{1 *}$ - Anita Štrkalj ${ }^{2}$ - Zoran Glavaš ${ }^{2}$
}

\begin{abstract}
${ }^{1}$ Department of Physical Metallurgy, Faculty of Metallurgy, University of Zagreb, Aleja narodnih heroja 3, 44103 Sisak, Republic of Croatia

${ }^{2}$ Department of Process Metallurgy, Faculty of Metallurgy, University of Zagreb, Aleja narodnih heroja 3, 44103 Sisak, Republic of Croatia
\end{abstract}

\begin{tabular}{l} 
ARTICLE INFO: \\
\hline Article history: \\
Received: 30.01 .2018$. \\
Received in revised form: 20. 06. 2018. \\
Accepted: 21.06 .2018$. \\
\hline Keywords: \\
Titanium alloys \\
Dental implants \\
Powder metallurgy \\
Porosity \\
Density \\
Microhardness \\
\hline DOI: http://doi.org/10.30765/er.39.1.12
\end{tabular}

\section{Introduction}

Biomaterials are a group of materials that are implanted in the human body with the aim of replacing the tissues and/or restoring their function. A biomaterial must have good mechanical, physical, and chemical properties. These requirements eliminate many engineering materials that are available. Metallic materials, particularly titanium and titanium alloys, often correspond with regard to the required properties. Titanium alloys have a low weight, good mechanical properties, especially low elastic modulus and low density. Chemical properties, such as corrosion resistance, are also very good [1,2]. Moreover, it is known that titanium

\begin{abstract}
:
Due to good properties, which meet the requirements for use as biomaterials, titanium and titanium alloys have been increasingly used as dental implants. Until recently, dental titanium alloys were produced by casting. Since this process does not meet the terms of economy and efficiency, the production of titanium implants by powder metallurgy are very promising. Therefore, in this work titanium alloy with addition of 10 at. \% zirconium is prepared by powder metallurgy with the goal of obtaining the best producing conditions, which would result in the titanium alloy of the adequate properties for use as dental implants. High values of green densities were achieved even only by uniaxial pressing. Further, sintering temperature of $1673 \mathrm{~K}$ resulted in the alloy of the highest sintered density and microhardness. The results of this investigation revealed the processing parameters applicable for the production of titanium-zirconium dental implants by powder metallurgy.
\end{abstract}

and its alloys have good biocompatibility with the human body, as well as antiseptic properties $[1,3]$. Because of these properties, titanium alloys are often used in dental medicine. A variety of these alloys with non-toxic elements are developed [4]. However, there is a lack of binary $\mathrm{Ti}-\mathrm{Zr}$ alloys, unfortunately, since the zirconium is a biocompatible element that also meets other requirements. Furthermore, titanium and zirconium have the same crystal structure and consequently the unlimited solubility in each other [5-7]. Besides, zirconium is a stabilizer of beta phase of titanium as a favourable phase in biomaterials, which results in satisfying properties [6,7]. Until recently, dental titanium alloys by casting into molds of appropriate

\footnotetext{
${ }^{*}$ Corresponding author. Tel.: +38544533381; fax: +38544533378

E-mail address: slokar@simet.hr
} 
shape were produced. This process is quite demanding and economically inefficient. The aim is to replace this process with a simpler and more efficient way. Therefore, dental alloys nowadays are produced more and more by powder metallurgy [8$10]$.

The powder metallurgy techniques are very promising due to almost waste-free net-shape forming of parts, as well as a lack of chemical inhomogeneity typical for castings [11]. One of the powder processing techniques is mechanical alloying which is a solid-state powder metallurgical process. For that purpose the starting materials are commercially pure powders mixed in the appropriate proportion in the ball mill. They are alloyed by repeated deformation/cold welding/fracture mechanisms under frequent mechanical impacts. Afterwards, mixed and milled powders are compacted and sintered in order to obtain the desired microstructure and properties $[12,13]$. In this research, the $\mathrm{Ti}_{90} \mathrm{Zr}_{10}$ alloy was synthesized by powder metallurgy with goal of obtaining the best manufacturing parameters, which would result in the greatest density and consequently the adequate properties for use in dental medicine.

\section{Experimental investigation}

In this study, samples of alloy of interest were prepared from powders of titanium (90 at. \%) and zirconium (10 at. \%) as raw materials. Single powders and powders mixture were analysed using the scanning electron microscope (SEM) Tescan Vega TS $5136 \mathrm{MM}$ and the Bruker energydispersive spectrometer (EDS). The SEM images of $\mathrm{Ti}$ and $\mathrm{Zr}$ powders are shown in Fig. 1 and their characteristics were listed in Table 1. Fig. 1 shows a different morphology of starting powders. Namely, titanium powder consists of spherical particles with rough surface (Fig. 1a), while zirconium powder consists of angular particle shapes (Fig. 1b). Further, a relatively high degree of agglomeration of titanium particles could be observed since the smallest particles were not separated from the powder. Powders were ball milled at a rotation rate of 200 rpm for 30 minutes.
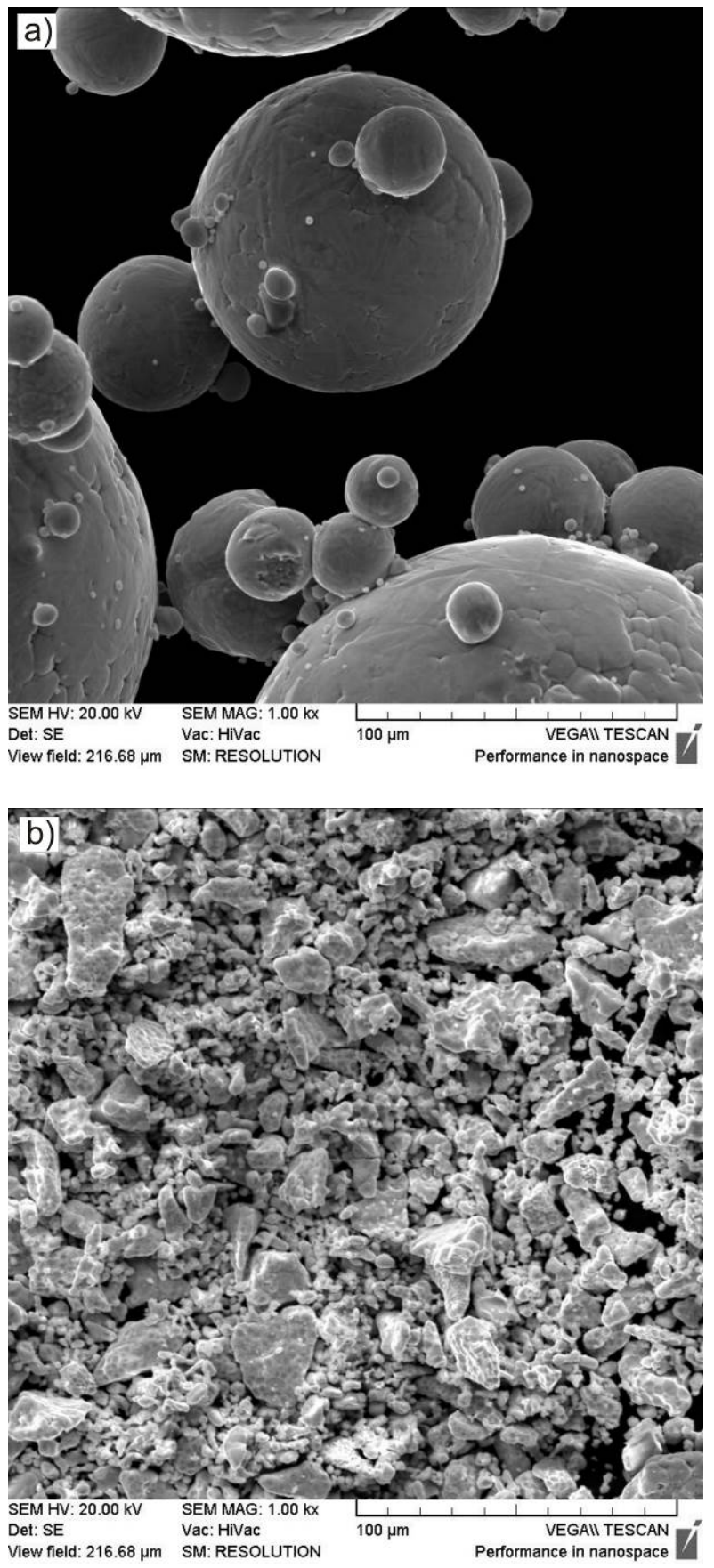

Figure 1. SEM images of a) Ti powder, b) $\mathrm{Zr}$ powder.

This process of mechanical alloying was carried out at room temperature in argon atmosphere (argon pressure was $0.5 \mathrm{MPa}$ ). Powders evacuation was performed into vessel in which argon pressure was 1.2 MPa to prevent the oxidation. Fig. 2 shows SEM image of $\mathrm{Ti}_{90} \mathrm{Zr}_{10}$ powders mixture after milling and corresponding EDS line analysis. It can be seen that many smaller particles still retained 
the original shapes since the particles were generally subjected to a low energy colliding. Just a small part of powders was agglomerated and deformed to a flake shape (Fig. 2a). The EDS line scan (Fig. 2b) confirmed that after milling there is an elemental zirconium remained indicating that milling parameters were not satisfying for completely zirconium dissolution in titanium.
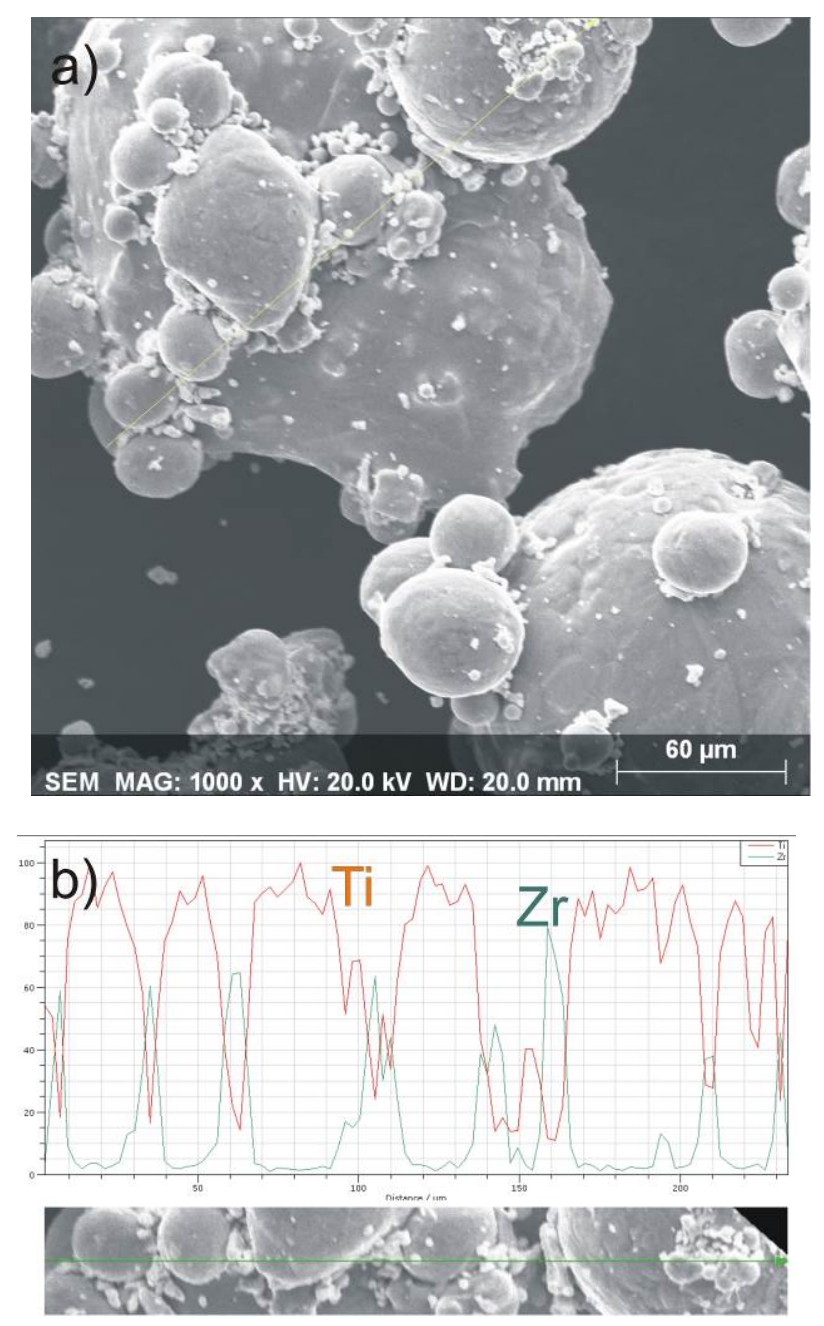

Figure 2. a) SEM image of $T i_{90} Z r_{10}$ powders mixture with marked line, b) EDS line analysis.

In the milling stage no lubricant was added in terms of obtaining the dental alloy by low-cost procedure. Namely, a lubricant addition would demand additional costs for its supply and afterwards removal. Afterwards, six samples were prepared by pressing the powder mixture in stainless steel die by uniaxial pressing at the room temperature to accomplish the powder densification. Compacting pressures were $200 \mathrm{MPa}$ for three samples (1-3) and $400 \mathrm{MPa}$ for another three (4-6) samples. They were applied to produce samples of cylindrical shape approximately $5 \mathrm{~mm}$ in diameter and $6 \mathrm{~mm}$ in height. Sintering process of obtained green compacts was conducted in a tube furnace under argon gas of $99.99 \%$ purity. The sintering was performed in the $\beta$-Ti area [5] at $1623 \mathrm{~K}$ for samples 1 and 5, $1673 \mathrm{~K}$ for samples 2 and 5 and $1723 \mathrm{~K}$ for samples 3 and 6 with 1 hour holding time at sintering temperature. The sintering procedure consisted of:

I. heating the samples at rate of $10 \mathrm{~K} / \mathrm{min}$ up to sintering temperature,

II. sintering; holding the samples at constant temperature for 1 hour and

III. cooling the samples in the furnace to room temperature.

In Table 2, pressing and sintering conditions are given.

For microscopic observations sintered specimens were grinded with $\mathrm{SiC}$ paper of different granulation and polished with water solution of 0.05 $\mu \mathrm{m} \mathrm{Al}_{2} \mathrm{O}_{3}$ on Buehler Phoenix Beta machine. Porosity was observed by light (Olympus GX51 microscope) and scanning electron microscope (SEM, Tescan Vega TS 5136 MM). Chemical homogeneity of sintered samples was analysed by Bruker energy-dispersive spectrometer (EDS). Their density was determined by means of Archimedes method using water. The densification coefficient, $\phi$, of the compacted samples was calculated using the following equation:

$$
\varphi=\frac{\rho_{S}-\rho_{g}}{\rho_{t}-\rho_{g}} \cdot 100 \%
$$

where $\rho_{s}, \rho_{g}$ and $\rho_{t}$ are the sintered density, density of green compact and theoretical density, respectively. The densities of green compacts were determined from dimensional measurements [11,14].

Microhardness was determined on ground and mirror-like polished sintered samples by Vickers method under the load of $1.961 \mathrm{~N}$ (HV0.2) during the 10 seconds using the microhardness tester Leica VMHT. 
Table 1. Characteristics of raw materials used in the Ti90Zr10 alloy preparation

\begin{tabular}{|l|c|c|c|c|}
\hline \multirow{2}{*}{ Material } & Purity & Particle size & Particle shape & Density \\
\cline { 2 - 5 } & $\%$ & $\mu \mathrm{m}$ & & $\mathrm{g} / \mathrm{cm}^{3}$ \\
\hline Ti powder & 99.9 & $125-250$ & Spherical & 4.51 \\
\hline Zr powder & 99.8 & $45-150$ & Angular & 6.49 \\
\hline
\end{tabular}

Table 2. Pressing and sintering conditions, time of sintering $1 \mathrm{~h}$

\begin{tabular}{|l|c|c|c|c|c|c|}
\hline \multicolumn{1}{|c|}{ Sample No. } & 1. & 2. & 3. & 4. & 5. & 6. \\
\hline Compacting pressure, MPa & 200 & 200 & 200 & 400 & 400 & 400 \\
\hline Sintering temperature, K & 1623 & 1673 & 1723 & 1623 & 1673 & 1723 \\
\hline
\end{tabular}

\section{Results and discussion}

In this research uniaxial pressing and sintering of samples was conducted in order to determine the influence of processing parameters on the densification of $\mathrm{Ti}_{90} \mathrm{Zr}_{10}$ alloy. Measurements of density were performed; three times for each sample and average values were given in Table 3.

Table 3. The densities of green compacts, $\rho g$ and sintered samples, $\rho s$, densification coefficient, $\phi$; $\rho t^{*}$ theoretical density

\begin{tabular}{|c|c|c|c|c|c|}
\hline $\begin{array}{c}\text { Sample } \\
\text { No. }\end{array}$ & $\rho_{\mathrm{g}}$ & $\%$ of $\rho_{\mathrm{t}}{ }^{*}$ & $\rho_{\mathrm{s}}$ & $\%$ of $\rho_{\mathrm{t}}{ }^{*}$ & $\phi, \%$ \\
\hline 1. & 3.57 & 76.77 & 3.47 & 74.62 & -9.26 \\
\hline 2. & 3.77 & 81.07 & 4.33 & 93.12 & 63.64 \\
\hline 3. & 3.71 & 79.78 & 3.60 & 77.42 & -11.70 \\
\hline 4. & 3.86 & 83.01 & 3.81 & 81.94 & -6.33 \\
\hline 5. & 3.75 & 80.65 & 3.83 & 82.37 & 8.89 \\
\hline 6. & 3.79 & 81.50 & 3.62 & 77.85 & -19.77 \\
\hline
\end{tabular}

The presented results show that high values of green densities were achieved even by only uniaxial pressing. Namely, all values are in the range from $76.77 \%$ to $83.01 \%$ of the theoretical density (4.65 $\left.\mathrm{g} / \mathrm{cm}^{3}\right)$. The standard deviations of green density values for samples 1 to 6 were as follows: 0.32, $0.28,0.32,0.24,0.30,0.28$. These variations in values are in accordance with porosity changes. It means that the lowest deviation i.e. measurement with the highest accuracy was accomplished in the sample with the highest green density (sample 4). Further, higher values were obtained (for samples 46) by higher pressure applied (400 MPa). Sintered densities in average are not much higher or they are even lower than green ones. The reasons for that are: the difference in diffusivity of titanium and zirconium during the formation of $\beta-\mathrm{Ti}$ solid solution, difference in particle size, entrapped air in pores, presence of impurities, etc. An exception is sintered density for sample 2, in which $93.12 \%$ of the theoretical density was achieved with coefficient of densification of $63.64 \%$. Another increasing of density by sintering was accomplished for sample 5. Its density is $82.37 \%$ of the theoretical and coefficient of densification is also positive (8.89\%). The remaining $\phi$ values are negative meaning that dimensional change related to sintered density is not satisfied. Dependence of sintered density on sintering temperature is presented in Fig. 3.

Standard deviations of sintered density values for samples 1 to 6 were as follows: $0.35,0.11,0.23$, $0.15,0.14,0.21$. These variations in values are also in accordance with porosity changes meaning that the lowest deviation i.e. measurement with the highest accuracy was accomplished in the sample with the highest sintered density (sample 2).

According to the binary phase diagram Ti-Zr [5], titanium and 10 at. \% of zirconium form beta-phase 
in unlimited area between $\sim 1173$ and $1823 \mathrm{~K}$. Therefore, it is important to determine a sintering temperature which would result in density closest to the theoretical one. As it can be seen in Fig. 3, the highest values of densities were achieved by sintering at medium applied temperature of $1673 \mathrm{~K}$. This shows that higher sintering temperature does not mean better densification.

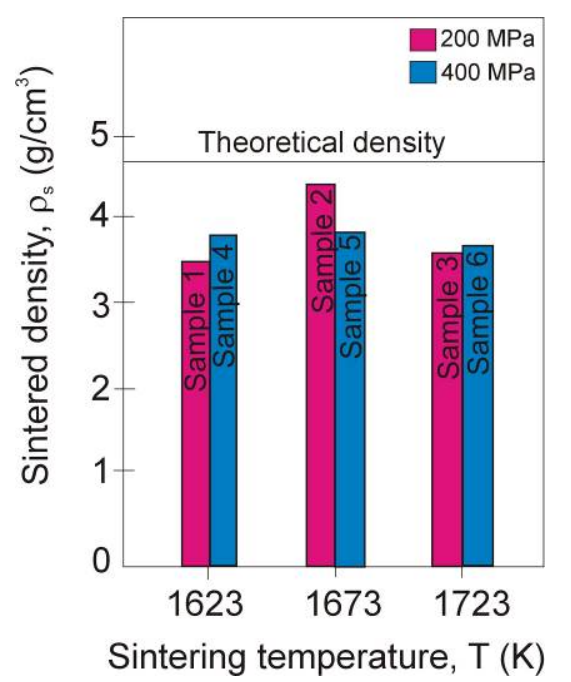

Figure 3. Sintered density as a function of sintering temperature.

The volume change is based on the exterior volume variation calculated from the cylindrical specimen and it is defined by following equation [15]:

$$
\frac{\Delta V}{V} \approx \frac{\Delta h}{h}+\frac{2 \Delta r}{r}
$$

where $V$ is the original volume of sample, $\Delta V$ is volume change, $h$ is height of sample, $\Delta h$ is height change, $r$ is radius of cylindrical sample and $\Delta r$ is change in radius of samples. The corresponding values of volume change as a consequence of dimensional change related to sintered density as well as a coefficient of densification as a function of the sintering temperature are shown in Fig. 4.

In Fig. 4, it can be seen that only samples 2 and 5 sintered at $1673 \mathrm{~K}$ undergo shrinkage. For the sample 2, volume is decreased for $2.71 \%$, while for sample 5, volume is decreased for $1.82 \%$. The other samples sintered at 1623 and $1723 \mathrm{~K}$ were increased in volume. The reason for this in accordance with the results for samples 2 and 5, could be found probably in insufficient sintering time rather than the compacting pressure. Still, better results were accomplished in paper [16] with niobium, which acts on titanium similar to zirconium. Satisfied sintered density was obtained in sample 2. From the above mentioned, it follows that the other results could be lower due to unsatisfactory parameters of powders mixing.
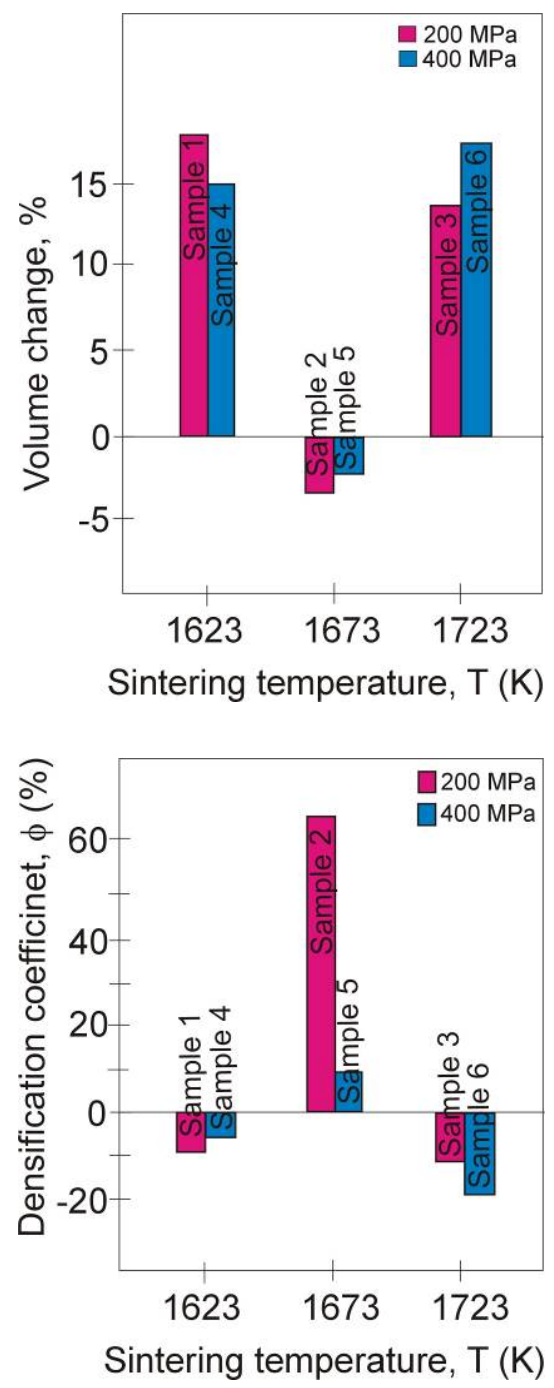

Figure 4. Volume change and densification as a function of the sintering temperature.

To reveal the grade of porosity, sintered polished samples were observed by light microscope. During the metallographic preparation by grinding and polishing sample 3 was broken. Therefore, microstructural observations and hardness measurements were performed on the five samples. Their micrographs taken with digital camera are presented in Fig. 5. In the micrographs (Fig. 5) 
anisotropic porosity can be seen, which is typical for a die-pressing and sintering processing.

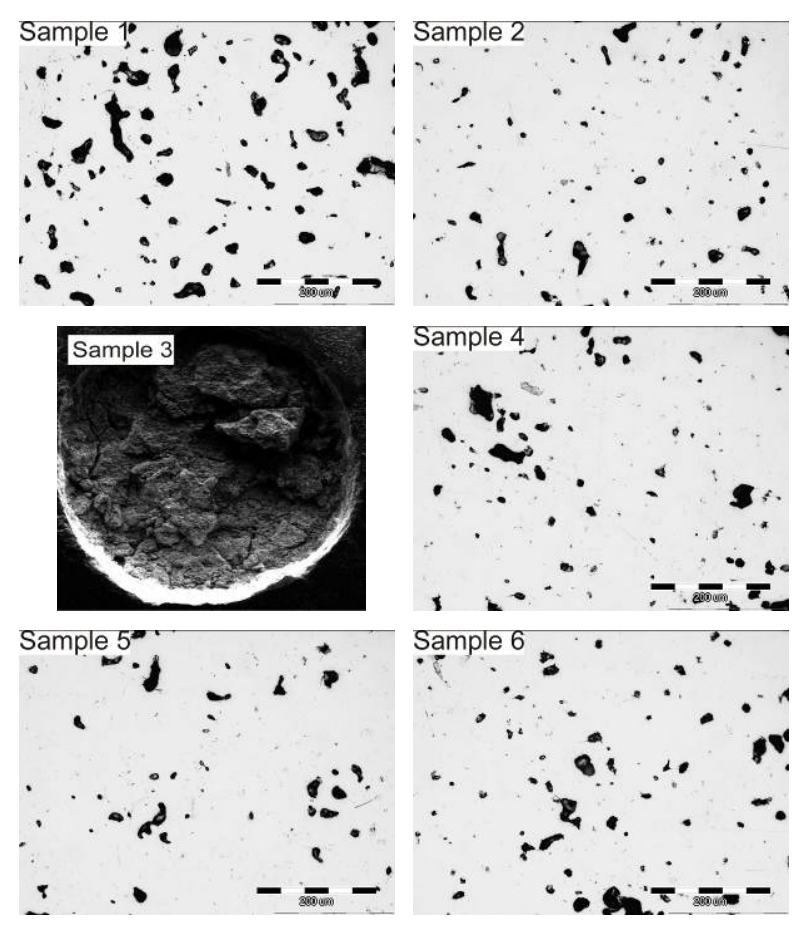

Figure 5. Optical micrographs of the porosity of sintered polished samples and SEM micrograph of broken sample 3, $200 \mathrm{x}$ magnification.

Throughout the die-pressing the pores have tendency to be flattened to a lenticular shape with the long axis perpendicular to the pressing. Pores become spherical and disappear in the final stage of sintering [17]. In this work, it is obvious that the last sintering stage was not finished since the relatively large amount of pores that had not been spheroidized is visible after sintering. In general, it depends on several factors, such as powder composition, green compact geometry and density, sintering atmosphere and temperature [11]. Due to reduction in size of pores during the sintering in the samples 2 and 5 the shrinkage did occur and consequently increase in density.

Chemical composition, as well as homogeneity of sintered samples by SEM using the energydispersive spectrometry (EDS) was determined. The results are given in Table 4 representing the semiquantitative chemical analysis performed by the EDS in point. According to the results of the EDS analysis, zirconium content in samples varies indicating that the mixing of starting powders was not properly performed, therefore compounds are inhomogeneous.

Table 4. Results of the EDS analysis

\begin{tabular}{|l|c|c|c|c|c|c|}
\hline & 1. & 2. & 3. & 4. & 5. & 6. \\
\hline Ti, at. \% & 94 & 89 & 94 & 93 & 88 & 95 \\
\hline Zr, at. \% & 6 & 11 & 6 & 7 & 12 & 5 \\
\hline
\end{tabular}

The EDS analysis in point showed that there is no other element present in powder mixture (Fig. 6).
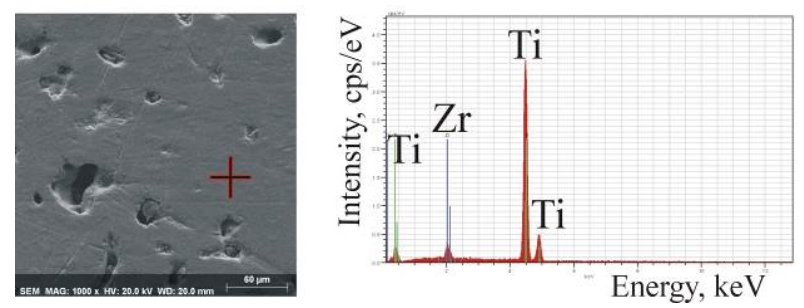

Figure 6. EDS spectrum for sample 1.

Namely, the EDS peaks for only $\mathrm{Ti}$ and $\mathrm{Zr}$ were found in all samples. The results in Table 4 reveal the best match with nominal composition for samples 2 and 5 which showed the best densification coefficient. The deviations in composition correspond to the achieved density meaning that large deviation corresponds to the lower obtained density.

The EDS line scan of sample 2 is given in Fig. 7. It shows regularly concentration profiles of only titanium and zirconium through default line.

The SEM micrograph of sample 1 along with the EDS mapping distribution of titanium and zirconium is shown in Fig. 8. It can be seen that titanium is uniformly distributed across the entire analysed area (Fig. 8b). Contrary, a different concentration of zirconium is visible across the examined area (Fig. 8c) implying unsatisfied powders mixing. Figure 8d shows the EDS mapping distribution of zirconium in sample 2, showing the best chemical homogeneity. 


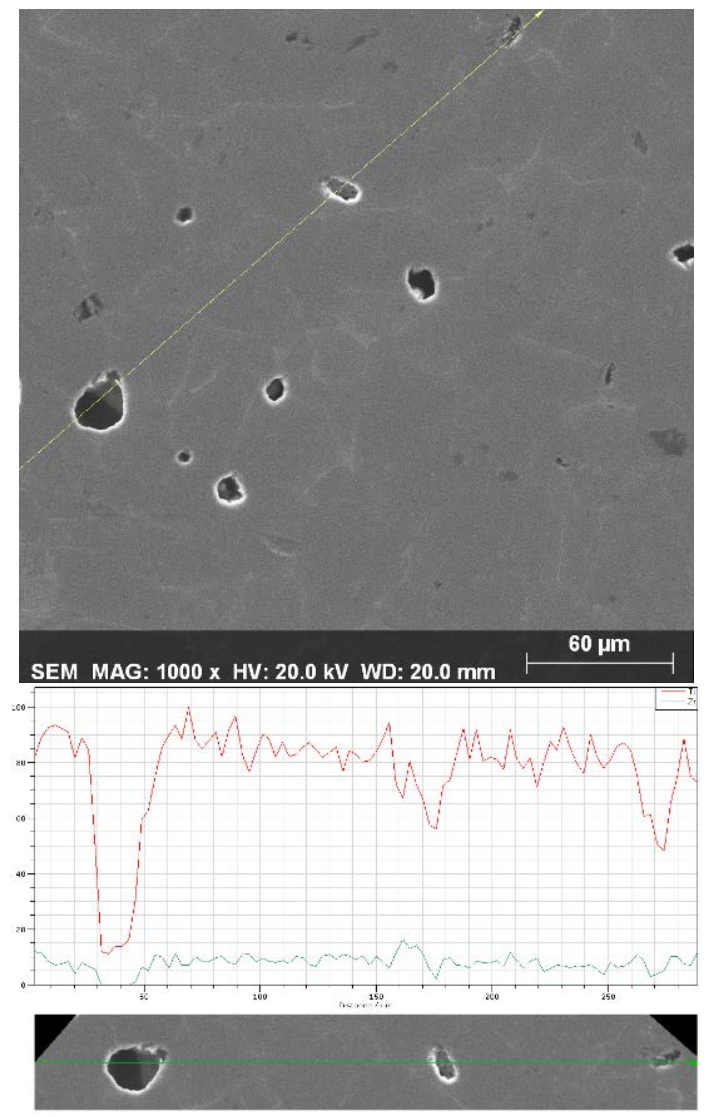

Figure 7. The EDS line scan of sample 2.

Vickers microhardness (HV0.2) measurements were conducted on the polished sintered samples in five spots and the average values were calculated. Since the sample 3 was broken during the metallographic preparation, its micro hardness was not determined. The determined HV0.2 values are in the range from 482 to 526 HV0.2, as presented in Fig. 9.

Standard deviation of microhardness values for sample 1 was 15.8, for sample 2 was 7.3, for sample 4 was 4.5 , for sample 4 was 15.2 and for sample 6 was 19.3. These values increase as HV0.2 values increase indicating the influence of porosity on microhardness measurements accuracy. Namely, sample 2 with the highest sintered density, i.e. the lowest porosity, showed the lowest deviation in HV0.2 values. Although measured Vickers microhardness values are similar for all samples, the presented results reveal the highest value (526 HV0.2) for sample 2. This can be attributed to the higher sintered density of sample.
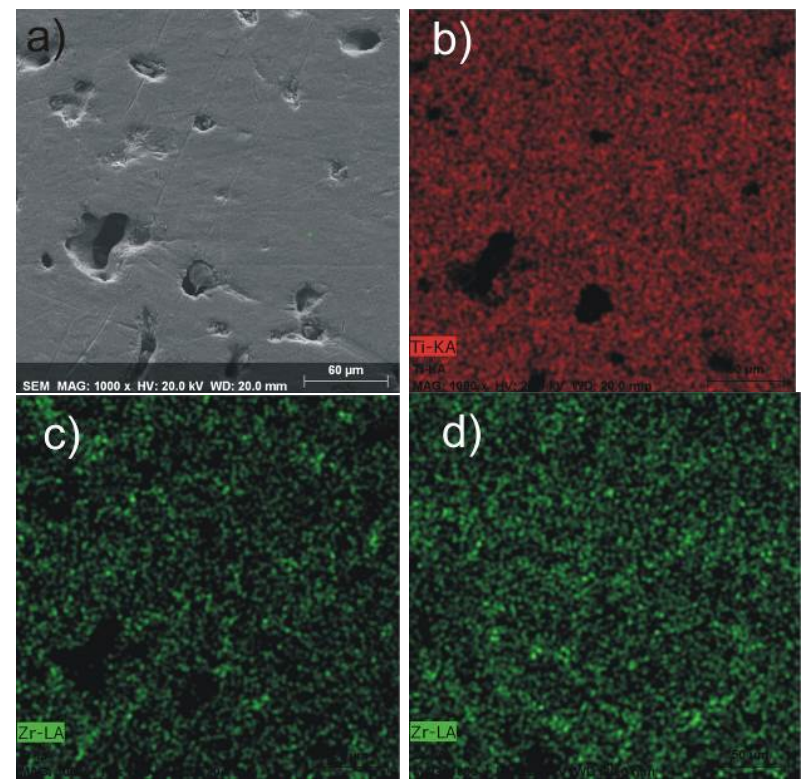

Figure 8. a) The SEM micrograph of sample 1, b) The EDS mapping of titanium distribution in sample 1, c) The EDS mapping of zirconium distribution in sample 1 and d) in sample 2.

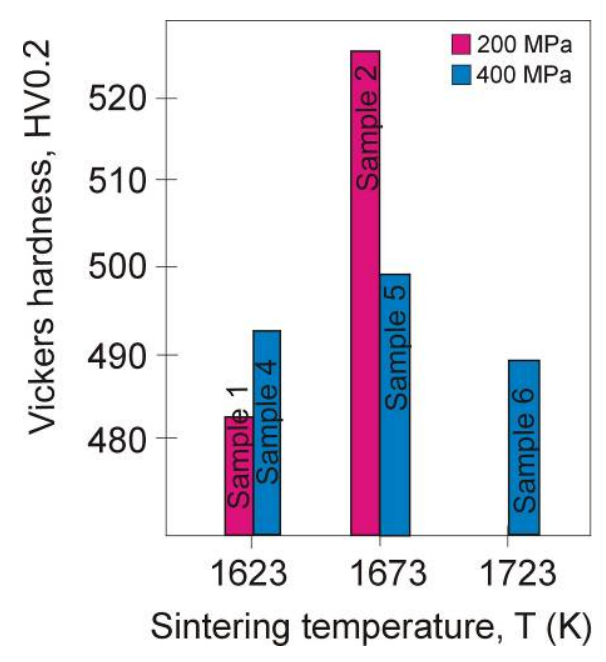

Figure 9. Vickers micro hardness as a function of the sintering temperature.

The list of measured values corresponds to the one for the achieved sintered densities indicating the increase in microhardness with increase in density (Fig. 10). The highest microhardness values were accomplished by sintering at $1673 \mathrm{~K}$. Microhardness values measured in this work are higher than similar binary Ti-Nb alloys produced by powder metallurgy $[13,18]$. The reason for this could be found in insufficient zirconium content and its uneven distribution in some samples. 


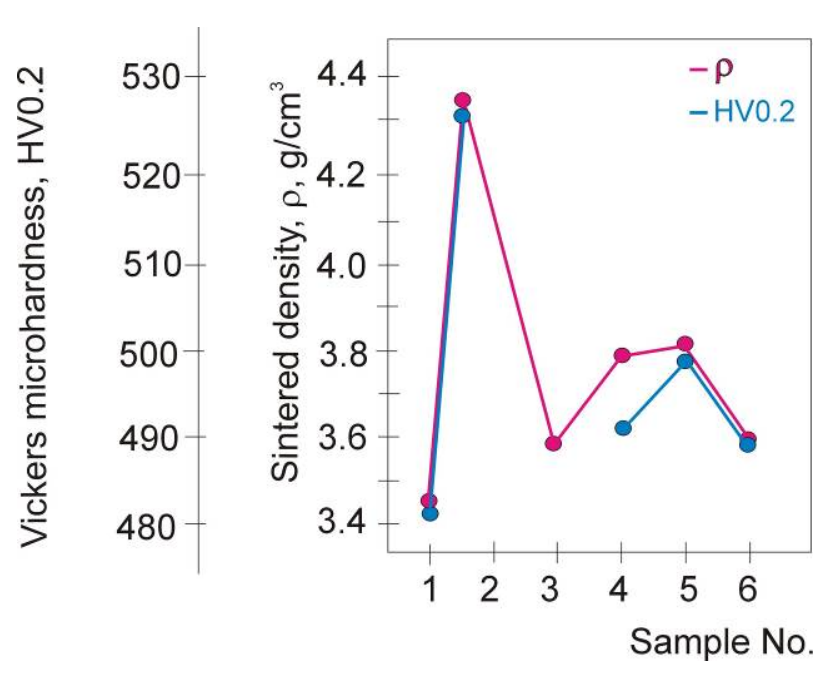

Figure 10. Comparison of Vickers micro hardness and sintered densities changes.

Microhardness can be further increased by increasing the sintering temperature because of additional particle-to-particle bonding and more complete alloying due to higher diffusion rates and mass transport [18]. It is obvious that sintering temperature should not be very high, i.e. on the upper limit of $\beta$-Ti area, since it would probably result in too high micro hardness values incompatible for dental applications.

\section{Conclusion}

The results in this research have shown that conventional powder metallurgy, as a cost-reducing technology is a promising way to produce a titanium alloy with zirconium addition for use in dental medicine. The sintering temperature was the processing parameter which together with chemical homogeneity showed the strongest influence on the microstructure and consequently on the properties. Inclusive, from the three sintering temperatures applied in this research, $1673 \mathrm{~K}$ resulted in the alloy with the highest. Higher compacting pressure (400 $\mathrm{MPa})$ resulted in higher and almost uniformed densities close to theoretical. It follows along with the measured microhardness values that Ti-Zr alloy synthetized by powder metallurgy has a potential for application as dental implants.

\section{Acknowledgement}

The authors would like to thank the „Magneti Ljubljana Ltd.“, „Alas-Info Ltd..“ and „SinterMAK Ltd.“ for their kind support during the samples preparation.

\section{References}

[1] Davis, J. R.: Handbook of Materials for Medical Devices, ASM International, USA, 2003.

[2] Reig, L., Tojal C., Busquets, D.J., Amigó, V., Microstructure and Mechanical Behavior of Porous Ti-6Al-4V Processed by Spherical Powder Sintering, Materials, 6 (2013), 48684878.

[3] Longhitanoa, G.A., Larosaa, M.A., Munhoza, A.L.J., Zavagliaa, C.A.C., Ierardia, M.C. C.F.: Surface Finishes for Ti-6Al-4V Alloy Produced by Direct Metal Laser Sintering, Materials Research, 18 (2015), 4, 838-842.

[4] Mohammed, M.T., Khan, Z.A., Siddiquee, A.N., Beta Titanium Alloys: The Lowest Elastic Modulus for Biomedical Applications: A Review, International Journal of Chemical, Nuclear, Metallurgical and Materials Engineering 8 (2014) 8, 726-731.

[5] Baker, H.: Alloy Phase Diagrams, ASM Handbook, Vol. 3, ASM International, Ohio, 2006.

[6] Mohammed, M.T., Development of a new metastable beta titanium alloy for biomedical applications, Karbala International Journal of Modern Science 3 (2017) 224-230.

[7] Hsua, H-C., Wu, S-C., Sung, Y-C, Ho, W-F, The structure and mechanical properties of ascast $\mathrm{Zr}-\mathrm{Ti}$ alloys, Journal of Alloys and Compounds488 (2009) 279-283.

[8] Arifin, A., Sulong, A.B., Muhamad, N., Syarifa, J., Ramli, M.I.: Material processing of hydroxyapatite and titanium alloy (HA/Ti) composite as implant materials using powder metallurgy: A review, Materials \& Design, 55 (2014), 165-175.

[9] Froes, F.H.: Titanium Powder Metallurgy: A Review - Part 1, Advanced Materials \& Processes, 70 (2012), 9, 16 - 22.

[10] Wang, H., Fang, Z.Z., Sun, P.: A Critical Review of Mechanical Properties of Powder 
Metallurgy Titanium, International Journal of Powder Metallurgy, 46 (2010), pp. 545-57.

[11]Dewidar, M.: Influence of processing parameters and sintering atmosphere on the mechanical properties and microstructure of porous 316L stainless steel for possible hardtissue applications, International Journal of Mechanical and Mechatronics Engineering, 12 (2012), 1, 10-24.

[12] Nouri, A., Chen, X., Li Y., Yamada, Y., Hodgson, P.D., Wen, C.: Synthesis of Ti-Sn-Nb alloy by powder metallurgy, Materials Science and Engineering A, 485 (2008), 562-570.

[13] Niespodziana, K., Jurczyk K., Jurczyk, M.: The Synthesis of titanium alloys for biomedical applications, Reviews on Advanced Materials Science, 18 (2008), 236-240.

[14]Bolzoni, L., Herraiz, E., Ruiz-Navas, E.M., Gordo, E.: Study of the properties of low-cost powder metallurgy titanium alloys by 430 stainless steel addition, Materials \& Design, 60 (2014), 628-636.
[15] Goi, K.L.S., Butler, D.L., Jarfors, A.E.W., Yong, J.M.S., Lim, D.C.S.: Elastic modulus of sintered porous $\mathrm{Ti}-\mathrm{Si}-\mathrm{Zr}$, using activation by Ti-Si mechanically alloyed powder and $\mathrm{TiH}_{2}$ powder, Materials and Science Engineering A, 475 (2008), 45-51.

[16] Santos, D.R., Pereira, M.S., Cairo, C.A.A., Grac, M.L.A., Henriques, V.A.R.: Isochronal sintering of the blended elemental Ti-35Nb alloy, Materials and Science Engineering A, 472 (2008), 193-197.

[17] German, R.M.: Sintering theory and practice, Wiley-Interscience, Hoboken, 1996.

[18] dos Santosa, D.R., Rodrigues Henriques, V.A., Alves Cairob, C.A., dos Santos Pereira, M.: Production of a Low Young Modulus Titanium Alloy by Powder Metallurgy, Materials Research, 8 (2005), 4, 439-442. 